\title{
UTILIZAÇÃO DE LIQUENS COMO BIOINDICADORES DA QUALIDADE DO AR EM ITABAIANA-SE
}

\author{
Erica Monteiro dos Santos ${ }^{(a)}$, Ricláudio Silva Santos ${ }^{(b)}$, Cristiano Aprígio Santos ${ }^{(c)}$ \\ (a) Departamento de Geografia, Universidade Federal de Sergipe - UFS, ericamonteiro1810@ outlook.com \\ (b) Departamento de Geografia, Universidade Federal de Sergipe - UFS, riclaúdio.silva@ @otmail.com \\ (c) Departamento de Geografia, Universidade Federal de Sergipe - UFS, aprigeo@ gmail.com
}

\section{EIXO: BIOGEOGRAFIA, MANEJO DE ÁREAS NATURAIS E PROTEGIDAS: CONSERVAÇÃO DA BIODIVERSIDADE}

\begin{abstract}
Resumo:
Os centros urbanos, hoje são áreas mais ocupadas e a poluição atmosférica passou a ser uma das maiores preocupações, a qualidade do ar vai interferir diretamente na qualidade de vida da população, frequentemente os efeitos da qualidade do ar não são tão visíveis, então para o diagnóstico podemos utilizar bioindicadores, esses podem dar visibilidade à pureza atmosférica. Para analisar a qualidade do ar do núcleo urbano de Itabaiana-SE, foram utilizados liquens como bioindicadores, pois os mesmos são sensíveis a alguns gases poluentes. Foram identificadas áreas em condições precárias o que reforça o estado de poluição, a principal área com índices satisfatórios fica no entorno da área mais arborizada, onde a biodiversidade tem maior expressão espacial, essa ocorrência demonstra a importante relação entre a manutenção da cobertura vegetal e suas associações ecológicas com o nível da qualidade do ar de um determinado local.
\end{abstract}

Palavras chave: Bioindicadores; Qualidade do ar; Itabaiana-SE.

\section{Introdução}

A priori sabe-se que a poluição atmosférica tem provocados impactos negativos ambientais e sociais. Os primeiros afetam o solo, influem na sua composição física, química e biológica, prejudicando a ciclagem dos nutrientes. Na atmosfera, causa a descoloração da mesma, a dispersão da luz solar quando há grande quantidade de partículas no ar, o aumento da formação de neblina e precipitação, além dos sérios riscos à sustentabilidade ambiental. Já o segundo trata-se das consequências que afetam diretamente a saúde da população, estas que resultam em problemas respiratórios, intoxicação, asfixia tosse, entre outras.

A pureza do ar atmosférico é fator crucial à sobrevivência dos líquens, pois estes se alimentam higroscopicamente, fixando elementos neles presentes, notadamente o nitrogênio. Os liquens absorvem e retêm elementos radioativos, íons metálicos, dentre outros poluentes, e isto faz com que sejam utilizados como indicadores biológicos de poluição atmosférica. (GONÇALVES et.al.,2007 apud NIOEBOER et.al., 1972 apud MOTA-FILHO et al., 2005; SEAWARD, 1977 apud MOTA-FILHO et al., 2005, p.01). 


\section{OS DESAFIOS DA GEOGRAFIA FÍSICA NA FRONTEIRA DO CONHECIMENTO \\ Instituto de Geociências - Unicamp \\ Campinas - SP \\ 28 de Junho à 02 de Julho de 2017}

Itabaiana situada no agreste sergipano (FIG.01) é considerada a quarta maior cidade do estado de Sergipe, com população de 86.967 habitantes (Senso do IBGE 2010), é conhecida como a capital do caminhão, por possuir um grande percentual de caminhão por pessoa do país.

Figura 01- Mapa de localização de Itabaiana, SE

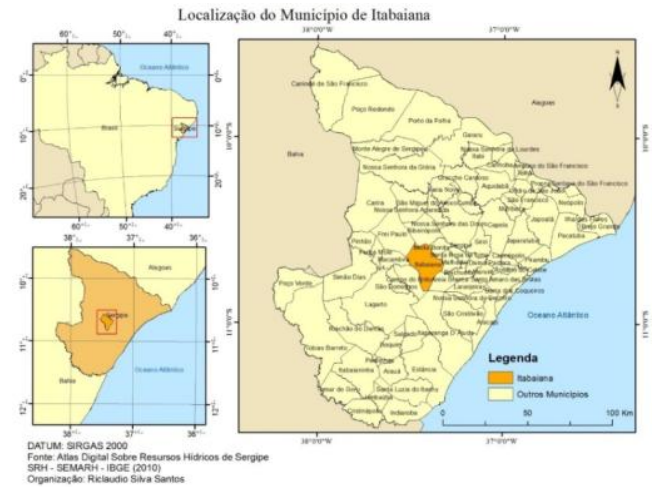

Fonte: Atlas Digital Sobre Recursos Hídricos de Sergipe.

Seu clima é semiárido, marcado por um período entre quatro ou cinco meses de seca, com temperaturas que variam de $20^{\circ} \mathrm{C}$ a $35^{\circ} \mathrm{C}$. É uma região de transição 'agreste', onde sua vegetação é formada por plantas de características litorânea e sertaneja.

Sua economia é caracterizada pela forte influência comercial no interior do estado. Tem suas atividades econômicas variadas que vai desde a agricultura de frutas e verduras, até a diversificação de indústrias (calçados, bebidas, cerâmicas, móveis, algodão, alumínio, carrocerias de caminhões). Esta última atividade econômica atrelada ao intenso tráfego veicular acaba interferindo na qualidade do ar, logo o presente trabalho tem como objetivo avaliar por meio da utilização de liquens como bioindicadores a qualidade do ar do núcleo da cidade de Itabaiana-SE.

\section{Material e métodos}

Nessa análise da qualidade do ar foram escolhidas algumas localidades, por terem o tráfego veicular intenso, além de serem afetadas diretamente com a fuligem da queima da palha da cana de açúcar oriundas dos municípios de Areia Branca, Riachuelo e Laranjeiras tradicionais produtores de cana de açúcar.

Foram selecionadas as seguintes avenidas: Eduardo Magalhães, Praça Fausto Cardoso, Chiara Lubic, Avenida Otoniel Dórea, Praça Etelvino Mendonça, Rua Percílio Andrade e Rua Felisbelo Machado de Menezes. Foram coletados dados quantitativos e qualitativos, através das árvores - que tivessem 
XVII Simpósio Brasileiro

de Geografia Física Aplicada

I Congresso Nacional

de Geografia Física
OS DESAFIOS DA GEOGRAFIA FÍSICA NA FRONTEIRA DO CONHECIMENTO

Instituto de Geociências - Unicamp

Campinas - SP

28 de Junho à 02 de Julho de 2017

comprimento e largura que abrangessem o quadrante (medindo 40x40 cm), existentes no decorrer de cada localidade. Para a coleta dos dados, fez-se necessário uso e preenchimento de formulário e o uso do GPS.

Para a realização do processamento dos dados trabalhados nesta pesquisa realizada, foi utilizado o pacote do software ArcGis, a partir da licença acadêmica obtida pelo site da ESRI: 〈http://www.esri.com/>, disponibilizando de suas ferramentas e acesso ao ArcMap e ao interpolador de KERNEL - que no contexto das geotecnologias faz referência a um método estatístico de estimação de curva de densidade, que para a Geografia é uma alternativa de análise do comportamento de padrões, onde o mapa é plotado através do método de interpolação a intensidade pontual de determinado fenômeno na área de estudo, tal que possibilita a observação do processo no mapa.

Em campo realizou-se o preenchimento do formulário para coleta de dados qualitativos e quantitativos da população liquênica nas avenidas já supracitadas. Os quadrantes e os formulários serviram de subsídio para calcular o IPA (Índice de Pureza Atmosférica) proposto por Sloover e Leblanc em 1968 - que foi utilizado para a elaboração do mapa, pois o IPA baseia-se fundamentalmente na diversidade de espécies de líquens epífitos numa determinada área, que permitem a realização de mapas de risco nos quais se marcam diferentes zonas em função do seu grau de contaminação atmosférica, englobando dentro da mesma zona, locais compreendidos dentro do mesmo intervalo de concentração de contaminantes, com a seguinte equação: $\mathrm{Si}+\mathrm{Vi}$. Qi/ 25/ 100. Onde Si, refere-se ao número de espécie da área; Vi refere-se à frequência de cobertura de cada espécie; Qi refere-se ao índice ecológico da espécie.

Considerando que: Deserto Liquênico corresponde à ausência de espécies de liquens < 1, indica um agravamento da poluição ambiental; a Zona de Luta equivale à variação $>1 \mathrm{e}<3$, indica uma zona onde o ar se encontra mais ou menos moderado no que se refere a sua qualidade e a Zona Normal, correspondente a variação > 3, indicam que os liquens crescem normalmente e indicam que o ar apresenta melhor qualidade.

\section{Resultados e discussões}

No que diz respeito à análise realizada no núcleo urbano de Itabaiana SE, constatou-se uma quantidade reduzida de liquens nas árvores analisadas, assim como mostra a (FIG 02), é explicada pela sensibilidade dos organismos frente a alguns poluentes como o Dióxido de Nitrogênio $\left(\mathrm{NO}_{2}\right)$, Dióxido de Enxofre $\left(\mathrm{SO}_{2}\right)$, Trióxido de Nitrogênio $\left(\mathrm{NO}_{3}\right)$, Óxido de Cobre $(\mathrm{Cu})$, Zinco $(\mathrm{Zn})$ e Chumbo $(\mathrm{Pb})$. 
Figura 02 - Presença de Liquens na cidade de Itabaiana - Se

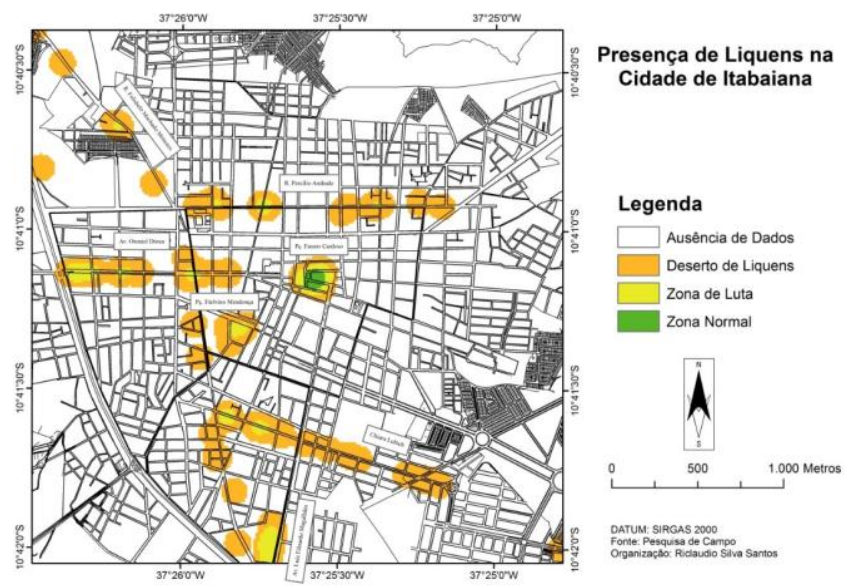

Fonte: Elaborado pela autora.

Na Rua Felisbelo Machado de Menezes, há predominância do Deserto Liquênico, com ressalva para uma pequena área de Zona de Luta; Na Rua Percílio Andrade, também há predominância do Deserto Liquênico, porém esta apresenta três áreas de Zona de Luta; Na Avenida Otoniel Dórea, a presença do Deserto Liquênico é mediana quando comparado às demais zonas evidenciadas em seu percurso, pois essa avenida há presença de quatro áreas de Zona de Luta; Na Praça Fausto Cardoso, há a presença do Deserto Liquênico reduzida, se comparada às demais localidades, além de ter uma área de Zona de Luta e uma área de extensão considerável de Zona Normal; Praça Etelvino Mendonça também com predominância de Deserto Liquênico, apresenta ainda uma pequena área de Zona de Luta; Na Avenida Eduardo Magalhães apresenta área de Deserto Liquênico e uma extensa área de Zona de Luta; por fim, o Chiara Lubic, que assim como as demais localidades tem a presença do Deserto Liquênico, mas que também possuem duas áreas de Zona de Luta.

\section{Conclusão}

Dos resultados obtidos e discutidos, constataram-se áreas com qualidade do ar comprometida. Entretanto, ficou evidente que a localidade com a melhor qualidade do ar é a Praça Fausto Cardoso, situada no núcleo urbano de Itabaiana - SE. Todavia, faz necessário considerar a necessidade do empreendimento de 


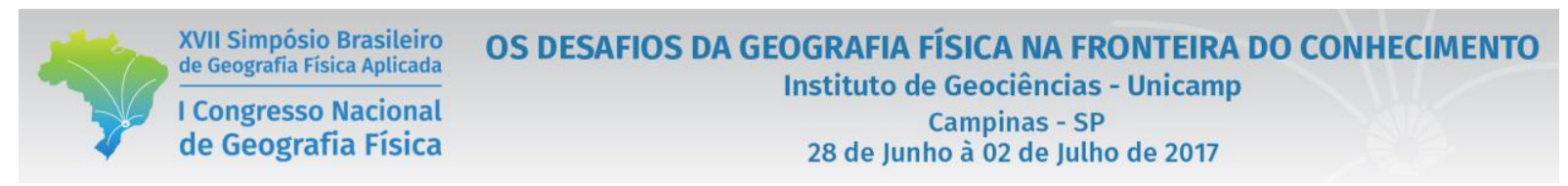

Políticas Públicas Ambientais, com a implantação de atividades de Educação Ambiental nas escolas e em outros locais da comunidade, execução de projetos de arborização para que assim, possa vir a recompor a biodiversidade urbana, ampliando a cobertura vegetal passível de colonização pelos liquens que consequentemente no futuro possam indicar melhora na qualidade do ar.

\section{Bibliografia}

GONÇALVES, V. F.; BRUNO, C. G. C.; SOUZA, C. R.; FAÇANHA, P. E. W.; ALVES, M. C.; BORGES, M. P.; MELO, C. Utilização de líquens como bioindicadores da qualidade do ar atmosférico da cidade de Uberlândia, MG. 2007, Caxambu-MG

IBGE, Cidades/municípios. Disponível em: Arquivo capturado em 19 de dezembro de 2017.

MEDEIROS, A. M. L, Mapa de Kernel - Conceito e Aplicações - Julho 2015. Disponível em: http://pt.slideshare.net/AndersonMedeiros/mapas-de-kernel-conceitos-e-aplicaes. Arquivo capturado em 19 de dezembro de 2017.

MOTA-FILHO, F. O.; PEREIRA, E. C.; SILVA, R. A.; XAVIER-FILHO, L. Líquens: Bioindicadores ou biomonitoradores. Portal Biomonitor, out. 2005. Disponível em: http://1 93. 136.140 .52 / b i o m o n i t o r /index.php?option=com_content\&task=view\&id=9\&Itemid=2. Arquivo capturado em 04 novembros 2016. 